\title{
Infant with swollen penis and apparent dysuria
}

\section{Sanemba Aya Fanny, Corrie Elizabeth Chumpitazi \\ Department of Pediatrics, Section of Emergency Medicine, Baylor College of Medicine, Houston, TX, USA}

Circumcision is a common elective surgical procedure performed worldwide. The Plastibell ring is a plastic device placed between the penis and the foreskin to circumcise a newborn male. This device is used routinely in neonatal circumcision, but complications such as bleeding, infection, and retention may occur. This case report describes the retention of a Plastibell device in a 21-day-old male and an innovative method to remove the device using a ring cutter. Emergency physicians should be aware of ring retention as a complication of the Plastibell ring and the proposed removal technique.

Keywords Circumcision, male; Urologic surgical procedures; Postoperative complications
elSSN: 2383-4625

Received: 14 December 2018

Revised: 29 January 2019

Accepted: 8 February 2019

Correspondence to: Sanemba Aya

Fanny

Department of Pediatrics, Baylor

College of Medicine, 1 Baylor Plaza,

Houston, TX 77030, USA

E-mail:fanny@bcm.edu

ORCID

http://orcid.org/0000-0003-2679-8738

\section{Capsule \\ Summary}

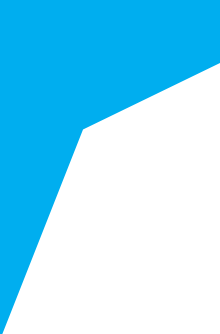

What is already known

Lower risks of urinary tract infections and sexually transmitted diseases are found in circumcised males. Circumcision with a plastic device is very common, yet rare but serious complications may occur.

What is new in the current study

Removal of a retained circumcision ring device using a ring cutter is an innovative and safe option in the emergency department especially when edema limits removal by traditional methods.

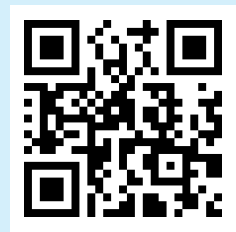

How to cite this article:

Fanny SA, Chumpitazi CE. Infant with swollen penis and apparent dysuria. Clin Exp Emerg Med 2020;7(2):136-138.

This is an Open Access article distributed under the terms of the Creative Commons Attribution Non-Commercial License (https:// creativecommons.org/licenses/by-nc/4.0/). 


\section{INTRODUCTION}

In the United States, approximately 59\% of newborn males undergo in-hospital circumcision after birth. The Plastibell device is one of the three most common methods used for this procedure, along with the Gomco clamp and the Mogen clamp., ${ }^{1,2}$ After manual lysis of adhesions between the glans and the prepuce, an appropriately sized Plastibell device is inserted on the glans. The prepuce is then tightly tied against the groove on the Plastibell device and allowed to necrose over the subsequent few days. ${ }^{1,2}$ The ring usually falls off spontaneously within 5 to 7 days. ${ }^{2}$ Studies report complication rates between $2.4 \%$ to $5 \%$, most commonly involving bleeding, ring retention, or proximal migration due to improper sizing. ${ }^{1-3}$ Consequences of retained rings include rare cases of scarring, glans necrosis, local infection, sepsis, and urethrocutaneous fistula. ${ }^{2,4}$

\section{CASE REPORT}

A 21-day-old term male presented to the emergency department with penile swelling, decreased urinary output, and parental concern for dysuria. On exam, his glans penis was edematous and erythematous, with an area of denuded skin on the penile shaft. The Plastibell circumcision device, placed on day 1 of life, was present and had migrated down the penile shaft (Fig. 1). He was otherwise afebrile and without signs of infection.

The patient received oral sucrose for analgesia by mouth (SweetEase solution, 24\% sucrose and water; McKesson Medical Surgi- cal, Richmond, VA, USA). An attempt was made to reduce the edema with the application of a thick mixture of granulated sugar and sterile water. After 15 minutes, gentle pressure was applied, but the glans could not be reduced through the Plastibell ring. Fig. 2 lists the stepwise approach to removal using a finger ring cutter (Fig. 3) without further trauma to the penis. The patient was discharged home with instructions to apply an antibacterial ointment to the penis until it healed. The patient's parent provided written consent to use photos for publication.

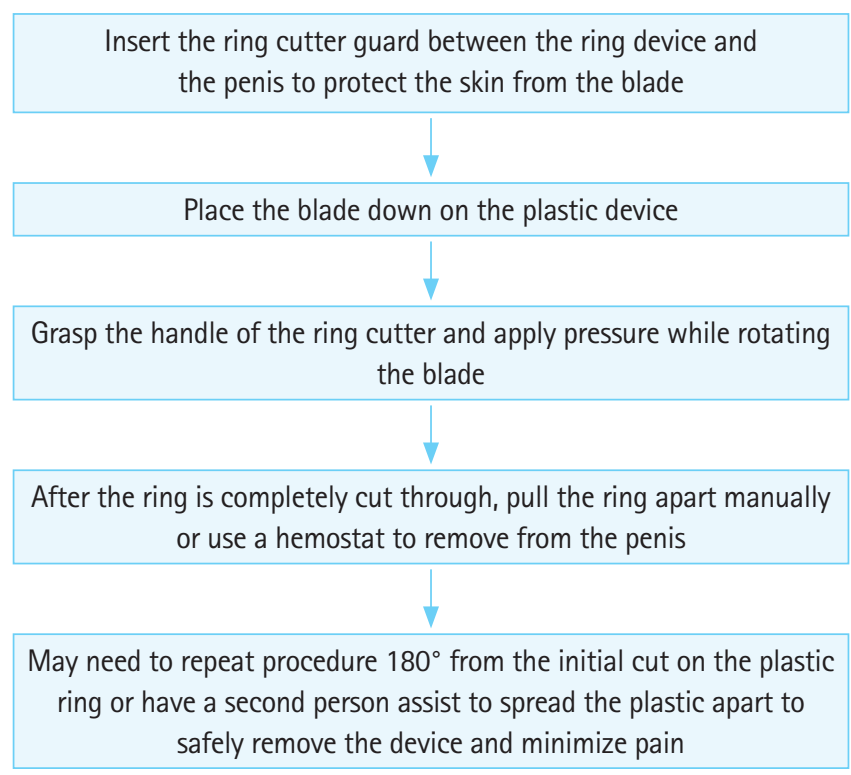

Fig. 2. Step-wise removal procedure.
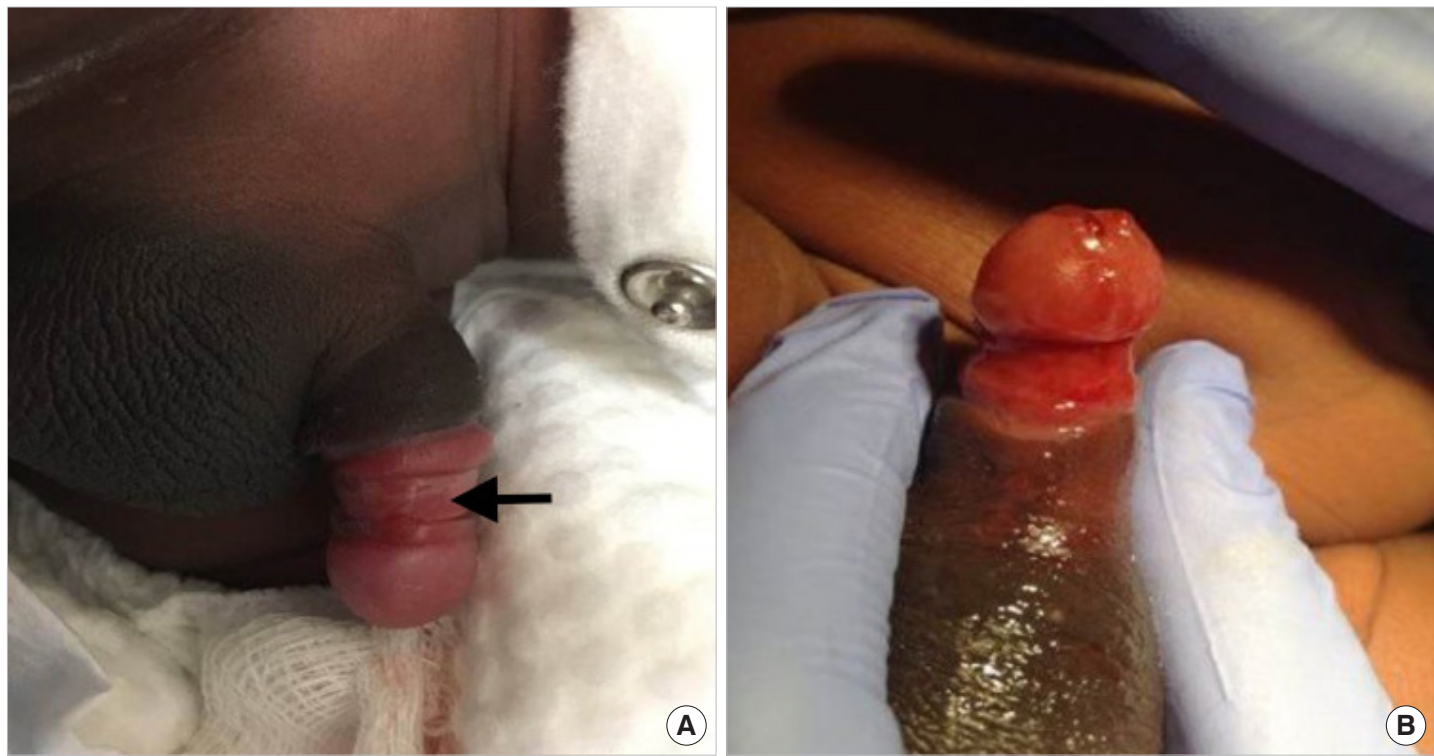

Fig. 1. (A) Swollen glans and denuded penile shaft with retained Plastibell ring (indicated by the black arrow). (B) Swollen glans after removal of the Plastibell ring. The patient's parent provided written consent to use photos for publication. 
¿EEM

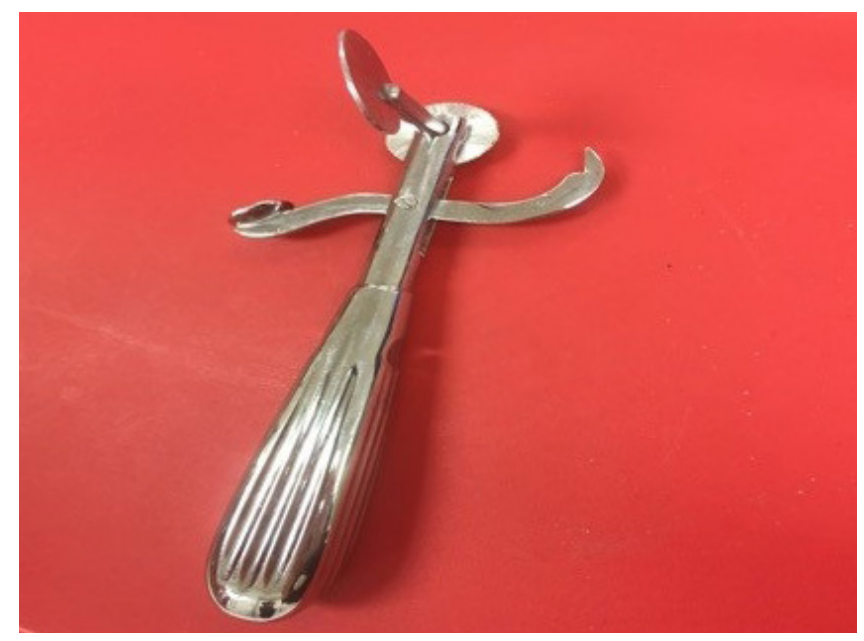

Fig. 3. Ring cutter device.

\section{DISCUSSION}

There is no unanimously agreed upon approach to removing retained Plastibell rings on infants. As reported by previous studies, using a ring cutter is a rapid, efficient, and safe method to remove retained and proximally migrated Plastibell rings after circumcision. ${ }^{2,3,5}$ These studies have been reported in surgical settings, and these patients may present to the emergency department where a ring cutter is often a standard supply. ${ }^{2,3,5}$ Other methods involve manual ring removal, for example, by removing the suture holding the Plastibell device in place and attempting to reduce the glans penis through the ring if it fails to be loosened by suture removal. ${ }^{3,6}$ Although manual methods do not involve the use of surgical instruments, they can cause significant pain and distress, and may incur further tissue damage through the manipulation of an already inflamed and painful penis. One study reports using disposable suture removal scissors to create a cut in the ring before prying it open using hemostats. Compared with removal using a ring cutter, this method has greater potential for injury, as it involves fragmenting the ring by force. While the use of traditional methods such as lubrication may be possible in the absence of edema, a ring cutter can safely and effectively be used to remove a retained device. Emergency physicians should be made aware of this simple and safe technique.

\section{CONFLICT OF INTEREST}

No potential conflict of interest relevant to this article was reported.

\section{REFERENCES}

1. American Academy of Pediatrics Task Force on Circumcision. Male circumcision. Pediatrics 2012;130:e756-85.

2. Smith AW, Hebra A, Mansfield JM, Streck CJ. Management of Plastibell circumcision ring migration and glans penis incarceration. J Pediatr Surg Case Rep 2013;1:186-8.

3. Jimoh BM, Odunayo IS, Chinwe I, Akinfolarin 00, Oluwafemi A, Olusanmi EJ. Plastibell circumcision of 2,276 male infants: a multi-centre study. Pan Afr Med J 2016;23:35.

4. Bode CO, Ikhisemojie $S$, Ademuyiwa AO. Penile injuries from proximal migration of the Plastibell circumcision ring. J Pediatr Urol 2010;6:23-7.

5. Palit V, Menebhi DK, Taylor I, Young M, Elmasry Y, Shah T. A unique service in UK delivering Plastibell circumcision: review of 9-year results. Pediatr Surg Int 2007;23:45-8.

6. Mousavi SA, Salehifar E. Circumcision complications associated with the Plastibell device and conventional dissection surgery: a trial of 586 infants of ages up to 12 months. Adv Urol 2008:606123.

7. Cilento BG Jr, Holmes NM, Canning DA. Plastibell complications revisited. Clin Pediatr (Phila) 1999;38:239-42. 